\title{
Experimental and theoretical study on piezoresistive properties of a structural resin reinforced with carbon nanotubes for strain sensing and damage monitoring
}

\author{
Giovanni Spinelli ${ }^{\mathrm{a}, *}$, Patrizia Lamberti ${ }^{\mathrm{a}}$, Vincenzo Tucci $^{\mathrm{a}}$, Luigi Vertuccio ${ }^{\mathrm{b}, * *}$ Liberata Guadagno $^{\mathrm{b}}$ \\ ${ }^{a}$ Department of Information and Electrical Engineering and Applied Mathematics University of Salerno, Via Giovanni Paolo II, Fisciano, SA, Italy \\ b Department of Industrial Engineering, University of Salerno, Via Giovanni Paolo II, Fisciano, SA, Italy
}

\section{A R T I C L E I N F O}

\section{Keywords:}

Carbon-carbon composites (CCCs)

Smart materials

Electrical properties

Mechanical testing

\begin{abstract}
A B S T R A C T
The development of embedded sensors based on a structural thermosetting epoxy resin reinforced with $0.3 \mathrm{wt} \%$ of multi-walled (MW) carbon nanotubes (CNTs) for real-time structural health monitoring is presented. The storage modulus of the composites is higher than $2000 \mathrm{MPa}$ in a wide temperature range confirming their reliability as structural parts, especially for aeronautical applications. The piezoresistive properties are studied on specimens subjected to both tension and flexural stresses. The yield strength evaluated with the same approach adopted for metallic materials and alloys compares successfully with the information provided by the electrical characterization. Different levels of damages are revealed by the changes in the piezoresistive properties due to the morphological modifications in the conductive network of CNTs within the resin. The analysis of an empirical law is proposed for predicting the strain-dependence of the electrical and mechanical properties of material when the samples are subjected to stretch-release cycles. The average CNTs interparticle distances as function of bending is also estimated.
\end{abstract}

\section{Introduction}

New materials like polymer composites based on carbon nanoparticles (nanotubes, fibers, graphene) are increasingly being used as aircraft primary structural parts (fuselage, cockpit, tail and wings) due their superior chemical and physical properties over traditional metallic materials or alloys [1-5]. In particular, low weight, high fracture toughness against impact damages, easy processability, resistance to corrosion, flame and moisture are some of attractive properties of polymer composites for aircraft applications. However, in order to extend the usage of such materials, their reliability has to be ensured in a safe, simple and economical manner. High mechanical stresses due to vibrations in adverse weather conditions and impact damages mainly due to birds or hailstones, lightning strikes represent a critical issue for aircraft composite structures [6]. In fact, the composite may undergo to considerable degree of deformation or cracks not visually detectable compromising the structural integrity of the components [7]. Therefore, much efforts are being devoted to evaluate the influence of defects on the strength and lifetime of structural materials and quantify the critical size of damage in order to introduce reliable methods for failure detection [8]. Traditional techniques based on visual inspection, ultrasonics, radiography, thermography are often slow, labour-intensive and not sufficiently sensitive to small damages. Moreover, they require a rather long deadlock of the scanned object, which leads to fewer flights of vehicles with consequent economic losses. Therefore, aeronautic industries are keen to apply faster and smarter damage detection methods based on distributed smart sensors. In particular, as it concerns the monitoring of advanced reinforced composites employed in structural components, sensors based on electro-active polymers or piezoelectric ceramics are not suitable since they are characterized by high fragility, non-negligible weight, need of high voltage or current for their correct use. An alternative approach may be represented by the use of polymer nanocomposites. The use of small amount of nanofillers, in particular carbon nanotubes, due to their tendency to easily form electrically conductive networks when embedded within polymer resins, may confer piezo-resistive properties to the resulting materials thus leading to a multifunctional component integrating structural and sensing capabilities [9-11]. A strictly relationship between the mechanical deformations and the electrical resistance exhibited by such advanced composite materials reveal their potential for applications as strain and damage sensing [12-14]. Structural health monitoring (SHM), mainly involves a nondestructive testing (NDT) system realized

\footnotetext{
* Corresponding author.

** Corresponding author.

E-mail addresses: gspinelli@unisa.it (G. Spinelli), plamberti@unisa.it (P. Lamberti), vtucci@unisa.it (V. Tucci), lvertuccio@unisa.it (L. Vertuccio), lguadagno@unisa.it (L.Guadagno).
} 
with integrated sensors able to continuous or periodic self-inspection for damage detection in situ. Ideally, it allows to recognize the damage type, the relative size and location thus minimizing the time and costs needed to take the structure out of service, then disassemble and inspect it [15-17]. Despite several studies aimed at investigating the strain sensing properties of composites reinforced with carbon-based nanofillers, some critical issues still remain to be clarified [18-22] in order to fully take advantage of their advantageous characteristics. In fact, the sensing performances may be different from the ones expected since it is not possible to avoid entangled aggregates due to a not uniform dispersion of the fillers within the resin which impacts on the load transfer between the two phases and affects the mechanical and the electrical response of the obtained nanocomposites. The main outcomes from several papers have been presented in a recent detailed review illustrating the physical phenomenon behind the piezoresistive properties of innovative and smart materials for strain sensors [23]. However, it is worth evidencing that most of the available works analyze the strain sensing properties of the nanocomposites by means of DC electrical characterizations, whereas only few refer to AC measurements [24-28].

In this paper an epoxy resin reinforced with $0.3 \mathrm{wt} \%$ of multi-walled carbon nanotubes (MWCNTs) is experimentally studied under axial and flexural stresses. In particular, after a preliminary morphological and thermomechanical analysis, aimed at confirming their suitable use in the aeronautical field as structural parts [1], the correlation between the mechanical response and the electrical properties are investigated for specimens subjected to fatigue tests. Set of cycles and different levels of intensity have been adopted for probing the long-term durability. The damage is expressed through a residual resistance strictly close to the amount of plastic strain accumulated in the matrix. Moreover, the dependence on strain of the piezoresistive properties is studied by considering numerical simulations allowing to analyze the impact of different physical parameters (i.e. interparticle separation distance, energy barrier) on the tunneling effect that governs the electrical resistance of the materials. The achieved results open the way towards the development of embedded sensors for structural health monitoring based on the same polymer composites employed for the fabrication of structural parts thus leading to multifunctional components integrating structural and sensing capabilities.

\section{Materials and methods}

The epoxy matrix was prepared by mixing an epoxy precursor, tetraglycidyl methylene dianiline (TGMDA) with an epoxy reactive monomer 1,4-butanediol diglycidyl ether (BDE) that acts as a reactive diluent. Instead, 4,4-diaminodiphenyl sulfone (DDS) is adopted as curing agent for this manufacturing process. All these components are provided by Sigma Aldrich. In order to obtain a uniform dispersion of the filler, the MWCNTs (3100 Grade purchased from Nanocyl S.A) were embedded into the matrix (Epoxy blend kept at $120^{\circ} \mathrm{C}$ to reduce the viscosity) by using an ultrasonication for $20 \mathrm{~min}$ (Hielscher model UP200S-24 kHz high power ultrasonic probe). After that, DDS hardener agent was added at a stoichiometric concentration with respect to all the epoxy rings (TGMDA and BDE). The tested specimens, in agreement with geometrical specifics (Fig. 1) of ASTM standards D638 and D790 $[29,30]$, were prepared according to a method described in Ref. [28]. Samples micrographs were performed with a field emission Scanning Electron Microscopy (SEM) apparatus (JSM-6700F, JEOL) instrument operating at $3 \mathrm{kV}$ on some nanocomposites section cut from the solid samples by a sledge microtome and suitably treated as already described in Guadagno et al. [31].

FTIR spectra were obtained at a resolution of $2.0 \mathrm{~cm}^{-1}$ with a FTIR (BRUKER Vertex70) spectrometer equipped with deuterated triglycine sulfate detector and a $\mathrm{KBr}$ beam splitter, using $\mathrm{KBr}$ pellets. The frequency scale was internally calibrated to $0.01 \mathrm{~cm}^{-1}$ using a $\mathrm{He}-\mathrm{Ne}$ laser. 32 scans were signal averaged to reduce the noise.
Thermogravimetric analysis (TGA) was carried out in nitrogen using a Mettler TGA/SDTA 851 thermal analyzer. The temperature range was $25-800{ }^{\circ} \mathrm{C}$ at a heating rate of $10^{\circ} \mathrm{C} \mathrm{min}{ }^{-1}$. Dynamic mechanical properties of the samples were performed with a dynamic mechanical thermo-analyzer (Tritec 2000 DMA-Triton Technology). Solid samples with dimensions $2 \times 10 \times 35 \mathrm{~mm}^{3}$ were tested by applying a variable flexural deformation in three points bending mode. The displacement amplitude was set to $0.03 \mathrm{~mm}$, whereas the measurements were performed at the frequency of $1 \mathrm{~Hz}$. The range of temperature was from $-60{ }^{\circ} \mathrm{C}$ to $320^{\circ} \mathrm{C}$ at the scanning rate of $3^{\circ} \mathrm{C} / \mathrm{min}^{-1}$.

Electro-mechanical tests (in axial and flexural strains according to ASTM standards D638 and D790, respectively) were performed, at room temperature, by using a Dual Column Tabletop Testing Systems (INSTRON, series 5967) set with a cross head speed of $1 \mathrm{~mm} / \mathrm{min}$ for both loading and unloading. More in details, a three point-bending measurements were carried out during the flexural tests. The corresponding force was measured by the machine load cell and converted to axial stress $(\sigma)$, whereas mechanical strain $(\varepsilon)$ was calculated as the machine crosshead displacement normalized by the gage length of the test specimen. Possible slipping during the displacement were excluded by recording local deformation by means of a conventional strain gauge (RS $5 \mathrm{~mm}$ Wire Lead Strain, gauge factor 2.1) having a gauge resistance of $120 \Omega$ (constantly measured with a precision multimeter HP $34401 \mathrm{~A}$ ), glued to one side of the specimen. A two-probe configuration based on an electrometer Keithley 6517A (configured in the double function of voltage generator and ammeter) was used to measure the current-voltage $(\mathrm{I}-\mathrm{V})$ characteristics between the copper electrodes fixed on the sample surface using silver paint (Silver Conductive Paint, resistivity of $0.001 \Omega \mathrm{cm}$ ) in order to ensure a good ohmic contact between the parts. Although simple, this measurement method, has successfully been applied in literature for resistance measurements in presence of tensile test $[32,33]$. Since the measured electrical resistance for all specimens was in the order of several $\mathrm{k} \Omega$, contact resistance was neglected. The same electrodes were used for the impedance spectroscopy (IS) analysis performed by using a precision LCR meter (model QuadTech 7600). The overall test setup and the geometrical features of the investigated specimens are reported in Fig. 1.

\section{Results and discussion}

\subsection{Structural, thermal and mechanical analysis}

The behavior related to the electrical properties of the nanocomposites reinforced with different filler amounts has been analyzed in depth in previous paper [28]. In the present work the sensing characteristics of the composites have been investigated for the sample loaded with of $0.3 \mathrm{wt} \%$ of MWCNTs. This concentration has been chosen because it is beyond the electrical percolation threshold (i.e. EPT) of the considered composite systems. Therefore, such composition is particularly suitable for achieving enhanced piezoresistive properties of the resulting material since the percolating network is more sensitive to small morphological variations due to mechanical strain [34-38]". In fact, the piezoresistive response is due to the modifications in the electrical network, e.g. loss of contact among CNTs [28,39] or change in the tunneling resistance due to the rearrangement of neighbour CNTs [40] as well as to intrinsic piezoresistivity of fillers subjected to deformations [41]. A structural analysis has been carried out in order to fully investigate the characteristics of the employed nanofillers and resulting nanocomposites. Geometrical features of the filler can be estimated from FESEM (Fig. 2 a) and TEM (Fig. 2 b) images of Fig. 2. All data are summarized in Table I reported as Fig. 2c The FTIR spectrum of MWCNTs (Fig. 2d) highlights that the walls of MWCNTs are not completely un-functionalized, as stated by the manufacturer. In particular, in the FTIR spectrum, together with expected signals (i.e. C-C stretch at $1640 \mathrm{~cm}-1$ and $1543 \mathrm{~cm}-1$, due to skeletal vibrations) other bands appear. In particular, the spectrum shows the presence of oxygenated 

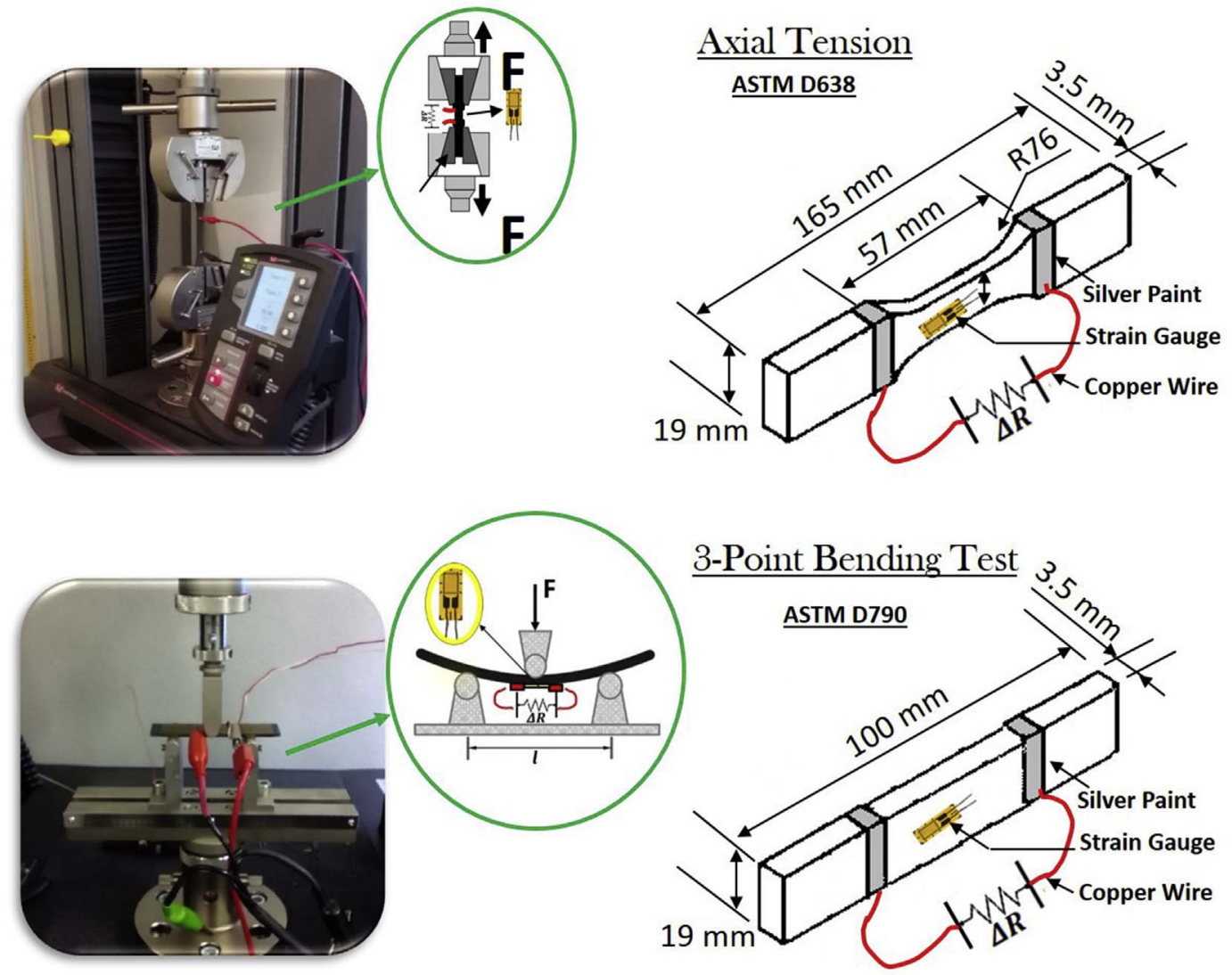

Fig. 1. Schematic representation of the experimental configuration and geometrical parameters of the specimens adopted for the piezoresistive characterization in tensile and bending tests.

a)

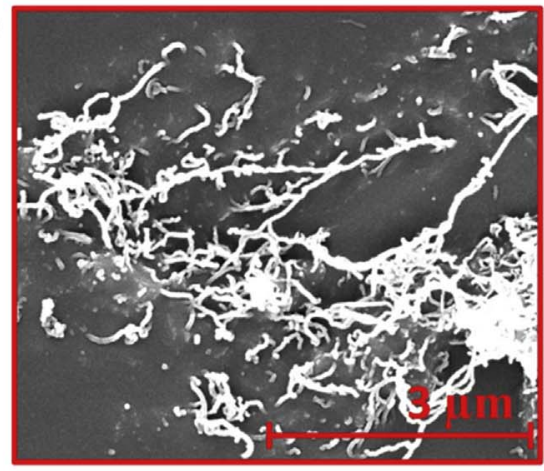

c)

TABLE I. Details of MWCNTS

\begin{tabular}{lcc}
\hline Subject & Parameter & Value \\
\hline CNT & Length (m) & $100 \times 10^{-9} \div 1 \times 10^{-6}$ \\
& Diameter (nm) & $10 \div 30$ \\
& Number of walls (/) & $4 \div 20$ \\
& Walls separation (nm) & {$[0.35]$} \\
\hline
\end{tabular}

b)

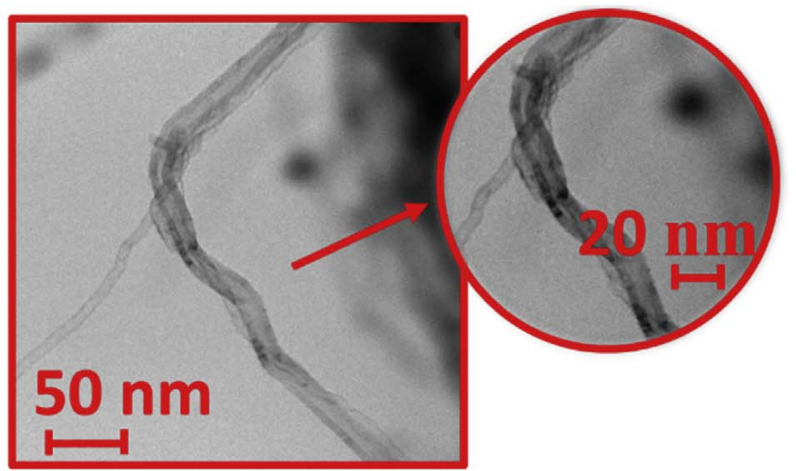

d)

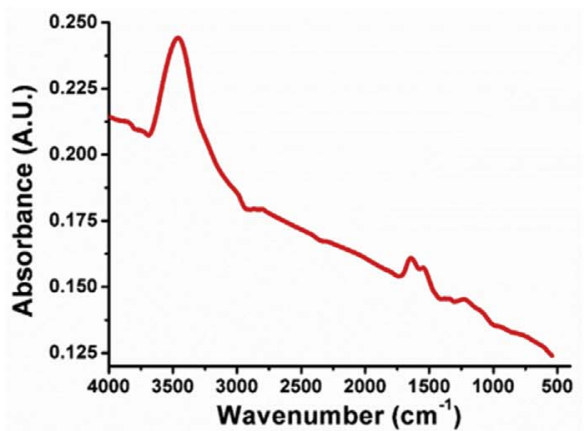

Fig. 2. a) FESEM image and b) TEM images of as-received multi-wall carbon nanotubes; c) Geometrical parameters of the filler (Table I); d) FT/IR spectra of the as-received multi-walled carbon nanotubes. 


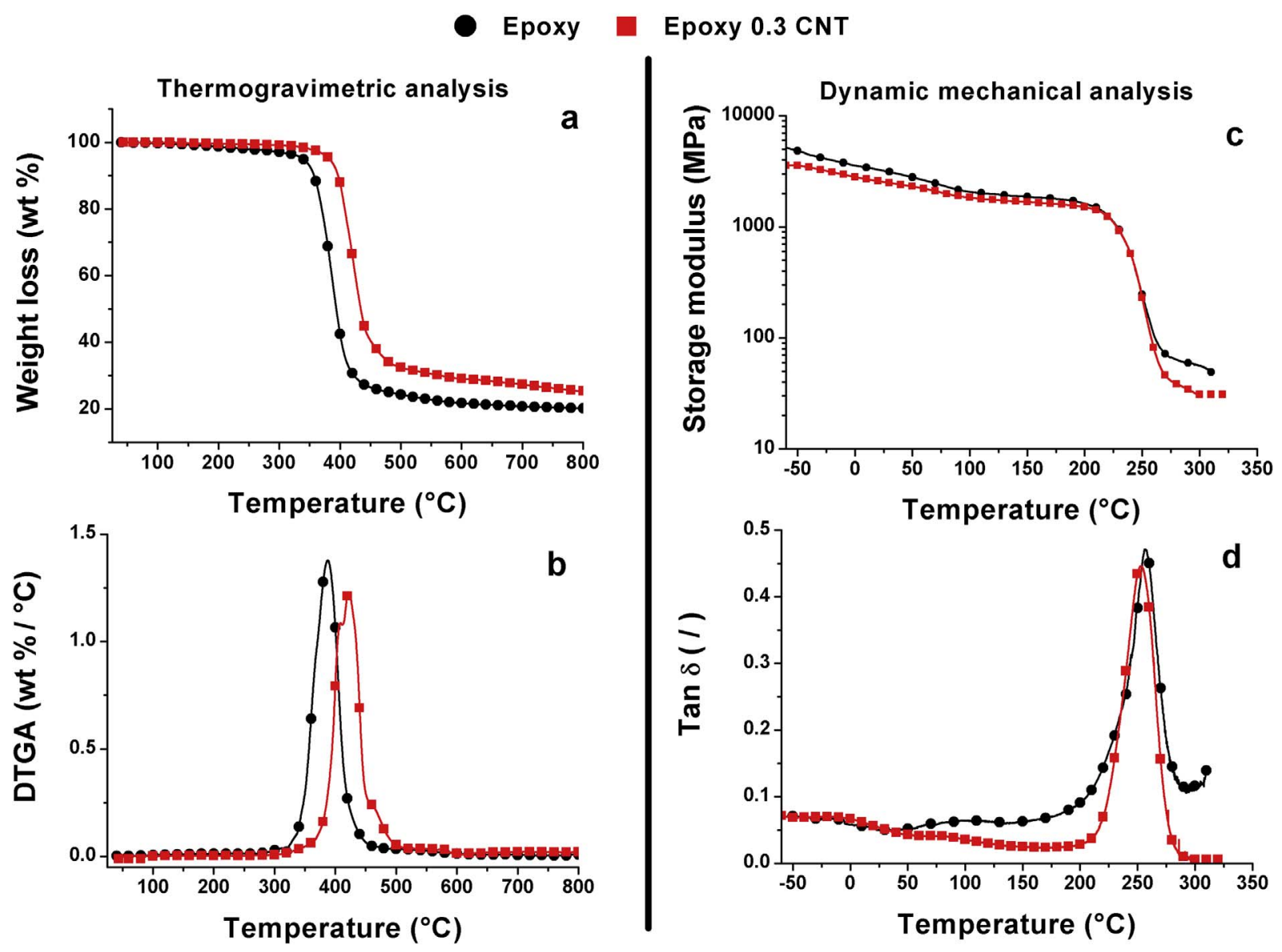

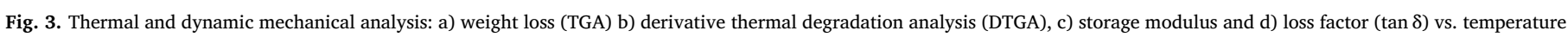
for neat resin (i.e. Epoxy) and nanocomposite filled with $0.3 \mathrm{wt} \%$ of carbon nanotubes (i.e. Epoxy $0.3 \mathrm{CNT}$ ).

functional groups (mainly hydroxyl and epoxide), whose concentration is not very negligible. The presence of different type of oxygen functionalities was confirmed by the bands at $3460 \mathrm{~cm}-1(\mathrm{O}-\mathrm{H}$ stretching vibrations), at $1220 \mathrm{~cm}-1$ (C-OH stretching vibrations), and at 1024 $\mathrm{cm}-1$ ( $\mathrm{C}-\mathrm{O}$ stretching vibrations). The presence of hydroxyl groups contributes to have a better distribution of the filler within the epoxy resin thus avoiding the agglomeration phenomena as observed and discussed in Ref. [28]. Polymers degrade through physical and chemical changes due to the reaction of their molecular components induced by the environment. At normal temperatures, polymers react slowly with oxygen and therefore oxidation becomes apparent only after a long time. However, degradation may be induced and accelerated by thermal energy and/or moisture, as well as exposure to radiation. Degradation in polymeric composites involves solid-gas reactions and it is associated with chain cleavage. As a result, the principal effects of degradation on polymers are the decay of mechanical properties such as strength, elongation and resilience, which is a problem common to polymer composites employed in critical conditions. An approach to determine the degradation rate is to measure the weight loss of a polymer specimen, which allows to investigate the overall degradation mechanism in polymer matrices. In order to evaluate the thermal stability of obtained composites, thermogravimetric analysis (see Fig. 3a and b) have been carried out. More in details, Fig. 3a shows the thermogravimetric curves for the neat resin (i.e. Epoxy) and nanocomposite reinforced with MWCNTs (i.e. Epoxy $0.3 \mathrm{CNT}$ ) evaluated in the temperature range $[30 \div 800]{ }^{\circ} \mathrm{C}$ under a nitrogen atmosphere. It is worth noting that, at the initial stage (before $400^{\circ} \mathrm{C}$ ), the unfilled resin begins to degrade earlier than the nanocomposite since the onset-degradation temperature $\left(5 \%\right.$ weight-loss temperature) ranges from $340{ }^{\circ} \mathrm{C}$ to $383^{\circ} \mathrm{C}$, respectively. Similarly, the maximum-rate degradation temperature, detected by the peaks of derivative thermal degradation analysis (DTGA) (see Fig. 3b), shifts from $389^{\circ} \mathrm{C}$ for pure resin to $422^{\circ} \mathrm{C}$ for the nanocomposite. The results from thermogravimetric experiments highlight that the MWCNTs produce a protection action like a barrier effect, which in turn prevents the transport of the products of degradation of polymer matrix from the solid (condensed) to the gaseous phase. This protection action may be due to the restriction of mobility of chain segments, caused by the presence of MWCNTs. As the restriction sites increases, there is a reduction in tension of $\mathrm{C}-\mathrm{C}$ bond induced by thermal action and hence the thermal stability of the epoxy matrix increases by about $20^{\circ} \mathrm{C}$. The thermal-mechanical stability of obtained composites has been investigated by dynamic mechanical analysis (DMA). In particular; the storage modulus and the loss factor (i.e. $\tan \delta$ ) of the unfilled and reinforced resin are shown in Fig. $3 \mathrm{c}$ and d, respectively. For both, the storage modulus is higher than $2000 \mathrm{MPa}$ in the wide temperature range of $[-60 \chi 100]{ }^{\circ} \mathrm{C}$ The profile of the curves in Fig. 3c shows a slow and progressive decrease of modulus up to $50{ }^{\circ} \mathrm{C}$. After that, an almost constant value follows in the range between $\left[50 \chi 200{ }^{\circ} \mathrm{C}\right.$ before the principal drop, due to the glass transition temperature (i.e. $\mathrm{Tg}$ ), which falls in the interval of $[200 \chi 300]^{\circ} \mathrm{C}$. The mechanical spectrum of the samples shown in Fig. 3d also confirms such value for the $\mathrm{Tg}$. In particular, the highest peak in the mechanical spectra, which is related to the glass transition, or $\alpha$ transition, is centred around $255{ }^{\circ} \mathrm{C}$ for the unfilled resin and the filled one. Therefore, the introduction of a very small amount of CNTs $(0.3 \mathrm{wt} \%)$ in a rigid composite does not affect significantly its modulus and its glass transition temperature value. Similar results have been observed also in our previous work [42]. Although the importance of the glass transition temperature on the mechanical properties of a material designed for strain sensor applications, this topic still remains scarcely discussed in 
literature. Therefore, the effect of CNTs on the $\mathrm{T}_{\mathrm{g}}$ is not yet fully understood. CNT may lead to a decrease of $T_{\mathrm{g}}$ due to their agglomeration tendency. On the other hand, results reported for MWCNT showed an increased or unchanged $T_{\mathrm{g}}$ of the composites [43]. The present available knowledge does not allow a clarification on this aspect due to the lack of a study providing essential information concerning purity of the filler (catalyst particles can affect cure reaction), glass transition temperature along with the corresponding cure degree (to isolate the true potential effect of CNT from curing variations). In our case, the introduction of CNTs does not lead to big differences in the curing kinetics behavior with respect to the unfilled epoxy [44]. For this reason, the resin and the composite have the similar curing degree. In any case, as already observed in our previous work [28], agglomeration phenomena of CNTs do not occurred. The absence of such phenomena allowed to keep the high $\mathrm{T}_{\mathrm{g}}$ value of the resin. In light of the previous considerations made, the sensor system, from the point of view of the material, has a thermal stability that remains unchanged up to $300^{\circ} \mathrm{C}$, maintaining high mechanical properties up to $100^{\circ} \mathrm{C}$. This ensures a high reliability if employed as structural aeronautical parts working in the normal operational temperature range. Moreover, the acquired greater thermal stability, obtained thanks to the introduction of the CNTs, allows a higher lifetime for polymeric composites under aircraft service, considering that properties such as stiffness, strength, density, deflection two to loading and/or environment, may change with the passage of time [45].

\subsection{Piezoresistive characterization}

\subsubsection{Tensile stress}

Fig. 4 shows the electro-mechanical response of the composite with $0.3 \mathrm{wt} \%$ of CNTs measured under axial tensile stress up to its failure around the $3.5 \%$ of strain at which a cracking discontinues the electrical measurements and leads to the specimen collapse. Therefore, in order to avoid breakage of the specimens, the levels of strain in all subsequent experimental characterization will be kept below this indicative critical value.

First of all, in order to identify the different operating regions, the mechanical loading (i.e. $\sigma$ ) plotted against the axial strain is reported on the left vertical axis. In particular, with reference to this plot, it is possible to evaluate the yield strength, a very important parameter for the structural design, as it represents the stress above which significant plastic deformations occur in the material. Since typically there is not a well-defined point at which the deformation transforms from an elastic to a plastic one, the yield strength is generally defined as the stress value for which the specimen under test shows a predetermined

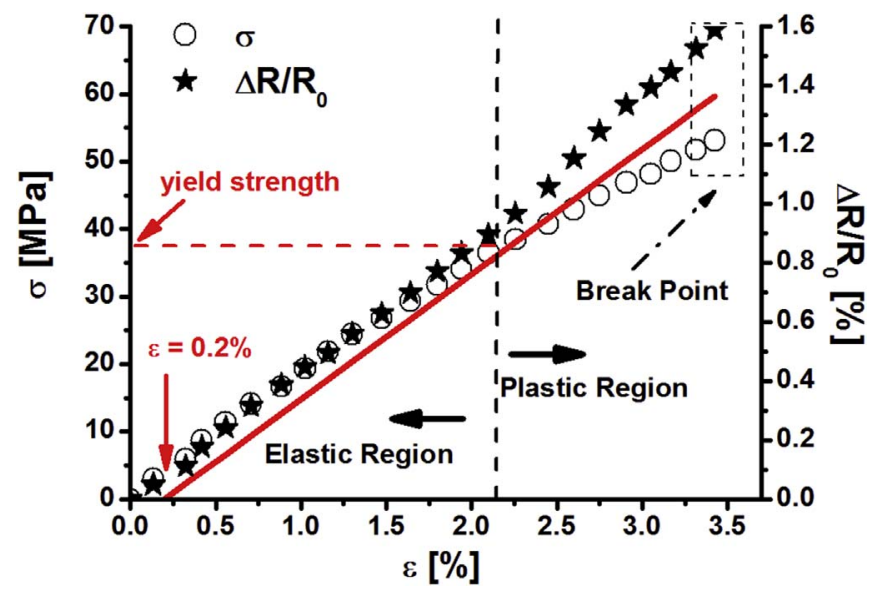

Fig. 4. Mechanical response (i.e. $\sigma$, left vertical axis) and normalized change of electrical resistance (i.e. $\Delta \mathrm{R} / \mathrm{R}_{0}$, right vertical axis) observed in tensile stress as function of the axial strain $(\varepsilon)$. residual permanent plastic strain typically equal to $0.2 \%$, as indicated in the stress-strain diagram [46]. More in details, the yield strength at $0.2 \%$ of residual permanent deformation is determined by the stressstrain diagram with the following procedure. First, a parallel line to the elastic stretch (linear response) of the diagram is drawn, starting from a deformation of $0.2 \%$. Hence, the meeting point of this line with the stress-strain curve provides the yield strength. In our samples a load of about $40 \mathrm{MPa}$ in correspondence of a strain of approximately $2 \%$ is detected. Therefore, indicatively, for strain values less than $2 \%$ the material exhibits an elastic response and above it a plastic one. It is worth noting that this approach, generally adopted for metallic materials or alloy, can be successfully applied also with our composites. In fact, the result agrees very well with that concerning the normalized change of electrical resistance (right vertical axis, Fig. 4) $\Delta R / R_{0}$, plotted against the axial strain $(\varepsilon) . R_{0}$ is the electrical resistance before any external mechanical strain (i.e. $\varepsilon=0$ ) and $\Delta R=R-R_{0}$ is the resistance variation caused by the applied axial tension. In particular, in the first region corresponding to the elastic response of the material the value of $\Delta \mathrm{R} / \mathrm{R}_{0}$ shows an initial linear dependence upon the applied strain and increases exponentially thereafter, most likely due to the occurrence of the first irreversible structure deformations when its response become plastic. Even with this type of characterization a limit strain, which discriminates the elastic/plastic response of material, of about $2 \%$ with respect to the rest position is identified according to the level previously identified with the yield strength. In any case, the increase of the overall resistance of the sample with increasing tensile strain support the assumption that in such nanostructured composites the electrical properties are strongly affected by the "tunneling effect" which requires that inter-particles distances must be sufficiently near to the so-called "tunneling distance" in order to allow an appreciable electron flow $[47,48]$. As a consequence of the imposed strain, it is plausible that change occur in the tunneling resistance between neighboring CNTs, due to the enlargement of inter-tube distance and/or a decreasing of the electrical contact areas. Both phenomena lead to an increase of the overall resistance shown by the material. For the evaluation of the sensitivity, the gauge factor $(G F)$ which relates the resistance change $\left(\Delta R / R_{0}\right)$ to the axial strain $(\varepsilon)$ is evaluated as: $G F=\Delta R / \varepsilon R_{0}$. In particular, the obtained value of 0.43 is derived as the slope of the line interpolating the experimental data of $\Delta \mathrm{R} / \mathrm{R}_{0}$ curve in the initial linear region. Moreover, as shown in Fig. 5, nanocomposites were subjected to cyclic tensile loading-unloading tests up to a maximum strain of increasing value (i.e. $0.83 \%, 1.65 \%$ and $2.42 \%$ ) during which piezoresistive properties were monitored.

It can be observed that in each cycle the maximum value of $\Delta R / R_{0}$ remain constant with the number of cycles thus indicating a regularity of the resistive behavior of the composites. It is interesting to note, for structural health monitoring purposes, that when strain falls in the elastic regime (i.e. $\varepsilon=0.83 \%$ and $\varepsilon=1.65 \%$ ) $\Delta \mathrm{R} / \mathrm{R}_{0}$ is null after each loading cycle since no significant permanent deformations, equivalent to an irreversible damage in the structure, have occurred in the composite. Instead, irreversible resistance changes, indicating permanent damages, are observed after a stretching (i.e. $\varepsilon=2.42 \%$ ) that overcomes the elastic response of the material. This behavior is due to the partial rupture of the electrical percolating network, as result of the rearrangement of the CNTs embedded in the polymer resin due to the plastic deformation (yielding) of the latter. This effect is interesting since the sensor may allow the detection of otherwise not viewable damages in the monitored structural part [30,33,49].

Given the potential of CNT-based composites to sense stress/strain even at almost imperceptible levels and the influence of several parameters such as type and functionalization of the filler on the piezoresisitve properties of the resulting materials, in addition to the experimental tests, reliable models and/or analytical solutions are highly desirable for optimization purposes of multifunctional sensing of the considered systems. To this aim, different numerical models and analytical approaches were presented in the literature [50,51]. 
a)
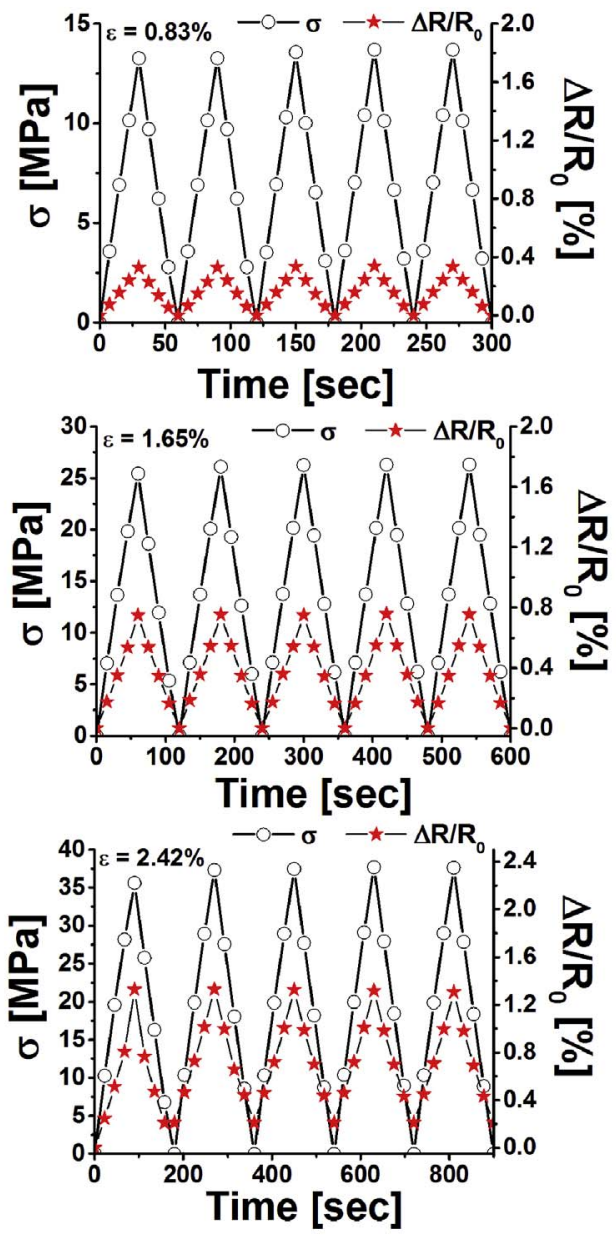

b)
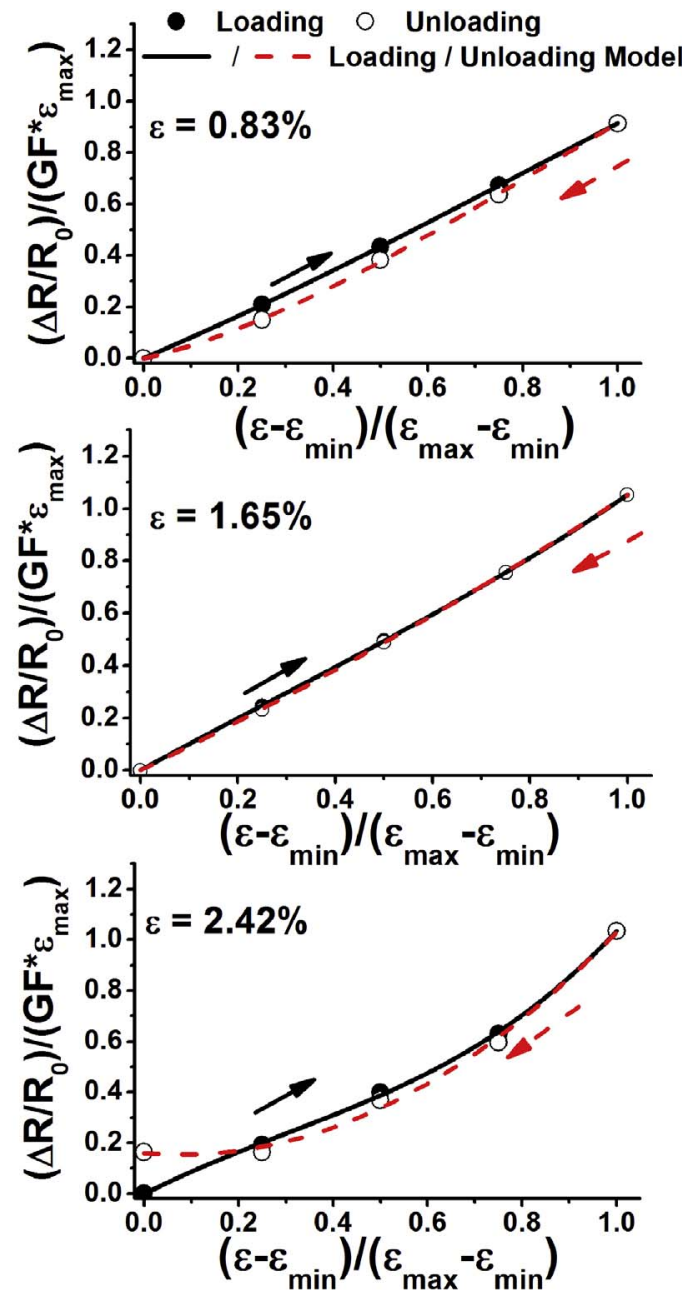

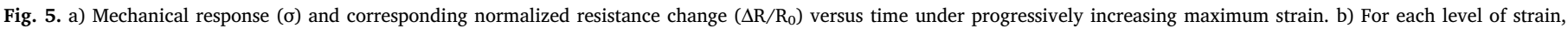
normalized experimental data and curve fitting (given by eq. (2)) for a cyclic loading-unloading results.

According to Ref. [52], the remarkable possibility to fit the experimental data for "stretch-release" cycles with the following relationship

$\frac{\Delta R}{R_{0}}=G F \cdot \varepsilon_{\max } f\left(\frac{\varepsilon-\varepsilon_{\min }}{\varepsilon_{\max }-\varepsilon_{\min }}\right)$

can be explored. In (1) $\varepsilon_{\max }$ and $\varepsilon_{\min }$ are respectively the maximum and minimum applied strain in a cycle and $f$ is a function of the variable $x=$ $\left(\varepsilon-\varepsilon_{\min }\right) /\left(\varepsilon_{\max }-\varepsilon_{\min }\right)$ which defines the so-called region of interest or region of experimentation of a reliable linear regression model [53]. In this region of applicability, the function $f(x)$ can be suitably approximated by a third order Taylor expansion [52]:

$f(x)=C_{0}+C_{1} x+C_{2} x^{2}+C_{3} x^{3}$

that is precisely a polynomial regression model in the unknown set of coefficients $\mathrm{Ci}$ with $\mathrm{i}=0,1,2,3$. Since in general polynomial models are linear functions of the unknown $C_{i}$, we refer to the technique as linear regression analysis. A collection of experimental data are required in order to evaluate such parameters. More in details, the estimation of these coefficients can be obtained by using them as parameters to maximize the coefficient of determination (i.e. $\mathrm{R}^{2}$ ) with an ordinary least squares (i.e. $O L S$ ) approach. In fact, the good correlation between the experimental data and eq. (1) is revealed by the coefficient of determination $\mathrm{R}^{2}$ strictly close to 1 for each interpolating curve. In particular, the four coefficients of eq. (2) can be derived from the analytic equations of the curves (black continuous curves refer to loading and red discontinuous to unloading cycles) shown in Fig. 5b. The different values of such parameters are collected in Table 1.

The term of zero order (i.e. $C_{0}$ ) is the most relevant one since it can give information on the structural integrity of the material. Almost zero values of $C_{o}$ (e.g. 0.0008) observed for the first and second loadingunloading cycles are indicative of no permanent deformation occurred in the material. Contrariwise, during the third unloading cycles, the coefficient $C_{O}$ assumes a not negligible value (i.e. 0.1589 ) since, an irreversible modification of the electrical percolating network leads to a residual resistance, indicative of an initial crack in the composite.

Instead, by analyzing the data, it is possible to observe that the coefficients $C_{1}, C_{2}, C_{3}$ may be associated to the strain-dependence of the electrical and mechanical properties of material. In each cycle and for each strain level the dominant coefficient is that relative to the linear term (i.e. the $C_{1}$ coefficient). The higher order coefficients (i.e. $C_{2}$ and $C_{3}$ ) increase, in absolute value, with increasing strain. This behavior is due to the mechanical-transition from the elastic to plastic response of material, as previously discussed with reference to Fig. 4. The usefulness and the interest of this theoretical approach lies in the fact that the potential damages of the structure can be captured, with a sort of memory effect, by exploiting a simple empirical law.

\subsubsection{Flexural stress}

Electro-mechanical bending tests were performed adopting a three point configuration on samples with a variable length (i.e. $l$, in $\mathrm{mm}$ ) of the support span, according to the sketch reported in Fig. 6a. In particular, the electrical measurements are conducted both in time and frequency domain. Moreover, cyclic bending tests were also carried out. 
Table 1

Coefficients of the regression analysis and relative coefficients of determination (i.e. $\mathrm{R}^{2}$ ) for each interpolating curve.

\begin{tabular}{|c|c|c|c|c|c|}
\hline Cycles & $C_{o}\left[\times 10^{-3}\right]$ & $C_{1}\left[\times 10^{-3}\right]$ & $C_{2}\left[\times 10^{-3}\right]$ & $C_{3}\left[\times 10^{-3}\right]$ & $R^{2}$ \\
\hline $1^{\text {st }}(\varepsilon=0.83 \%)$ Loading & 0.2 & 778.4 & 218.0 & -83.4 & 1.00 \\
\hline $1^{\text {st }}(\varepsilon=0.83 \%)$ Unloading & 0.8 & 428.6 & 817.8 & -333.4 & 1.00 \\
\hline $2^{\text {nd }}(\varepsilon=1.65 \%)$ Loading & -0.2 & 1018 & -358.3 & 192.5 & 0.99 \\
\hline $2^{\text {nd }}(\varepsilon=1.65 \%)$ Unloading & -0.3 & 906.5 & 122.1 & 23.6 & 1.00 \\
\hline $3^{\text {rd }}(\varepsilon=2.42 \%)$ Loading & -20 & 950.2 & -.772 .0 & 858.0 & 0.99 \\
\hline $3^{\text {rd }}(\varepsilon=2.42 \%)$ Unloading & 158.9 & -143.7 & 981.8 & 32.8 & 0.99 \\
\hline
\end{tabular}

A strain gauge positioned in the central part of the surface of the specimen is adopted in order to obtain experimentally the displacement (i. e. $\varepsilon_{\text {flexural }}$ ) induced by the applied force $F$ rather than evaluating it by using the theoretical relation:

$\varepsilon_{\text {flexural }}=\frac{6 D t}{l^{2}}$

where $D$ is the maximum deflection of the center of the sample (mm) and $t$ is the thickness of the sample (mm).

As evident from Fig. $6 \mathrm{~b}$, the normalized change of electrical resistance $\Delta \mathrm{R} / \mathrm{R}_{0}$ vs. flexural strains (left axis) follows an exponential trend.

Therefore, there is an evident different piezoresistive response respect to the applied strain (tensile or flexural). In case of tensile stress, the material reacts with a uniform stretching in the entire cross-section of the load application. Hence, the percolating network shifts rigidly with the force and the electrical response is linear.

Under flexural stress the electrical response of the material is determined by a combination of compressive and tensile stresses leading to specimen curvature. As a result, the tunneling resistance between conductive particles which is strongly sensitive to distance variations, affects more significantly the electrical response of the material thus originating the exponential dependence of the $\Delta R / R_{0}$ vs. strain [28]. Moreover, also the results concerning the mechanical tests are reported (inset of. Fig. 6b) in order to identify a potential boundary between elastic and plastic behavior of the material. Such a threshold is around $2 \%$ of strain. Fig. 7 shows the mechanical-electrical correlations obtained during flexural tests. Form Fig. 7a it possible to note that, at a given value of deflection (i.e. $D$ ), a decrease in the support span length (i.e. $l$ ) leads to an increment of flexural load (i.e. $\sigma$ ).

This behavior agrees with the theoretical relation based on bending momentum law [54]:

$D=\frac{2}{3} \frac{\sigma(l / 2)^{2}}{E \cdot t}$ where $E$ is the Young modulus.

As a consequence, this higher resulting load (for a fixed $D$ ) is detectable from more appreciable deformations of strain-gauge (Fig. 7b). Similarly, the composite material permits to reveal such aspect by evaluating the normalized resistance changes (Fig. $7 \mathrm{c}$ and d) although with an exponential trend rather than with the linear one exhibited by the strain gauge.

Such different response is due to the fact that the strain gauge reads only the superficial material deformation (i.e. elongation strain, $\sigma_{t}$ of Fig. 6a), whereas the electrical response of the composite is affected by two more complex and coexisting dynamic effects. In particular, inflections generated by bending moment determine also compressive actions (i.e. $\sigma_{c}$, see Fig. 6a), as already described in Vertuccio et al. [28], responsible of such resulting non-linear behavior. In brief, internal compressive stresses reduce the insulating spacer of resin between the conductive particles whereas internal tensile stresses lead to their separation. With increase of specimen curvature the elongation strains of resin will predominate over the compression ones. As a consequence, the tunneling resistance between nanotubes, particularly sensitive to such distances, affects more significantly the electrical response of the material thus originating the exponential dependence of the $\Delta R / R_{0}$ versus strain.

Moreover, the piezoresistive behavior of the nanostructured composites arises from tunneling (i.e. $R_{\text {tun }}$ ) between two conductive inclusions in agreement with the following expression:

$$
R_{\text {tun }}=\frac{h^{2} d_{0}}{S_{\text {cnt }} e^{2} \sqrt{2 m E_{c}}} \exp \left(\frac{4 \pi d_{0}}{h} \sqrt{2 m E_{c}}\right)
$$

where $S_{c n t}$ is the cross-sectional area of the CNTs, $h$ is the Plank's constant, $d_{o}$ is the interparticle separation distance, $e$ is the electron charge, $E_{c}$ is the energy barrier and $m$ is the electron mass [48].

In this case, as observed also for graphene-based polymer resins [55], it is possible correlate the effect of strain upon the electrical resistance by means of the following relationship:

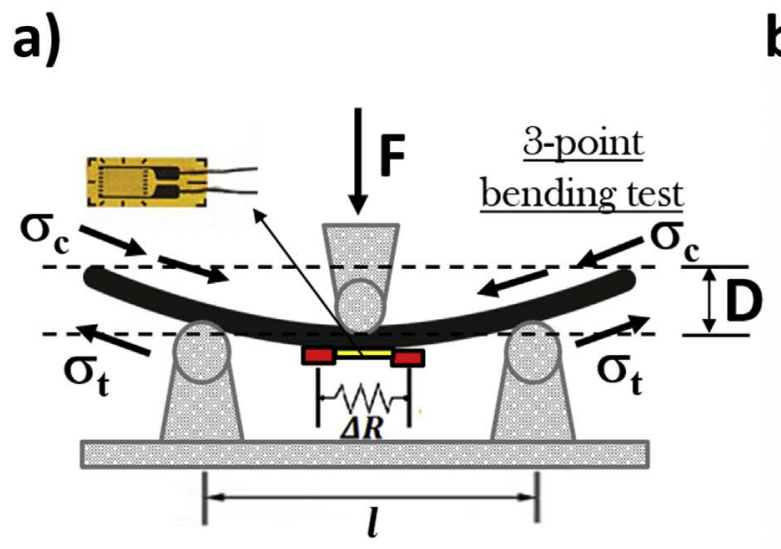

b)

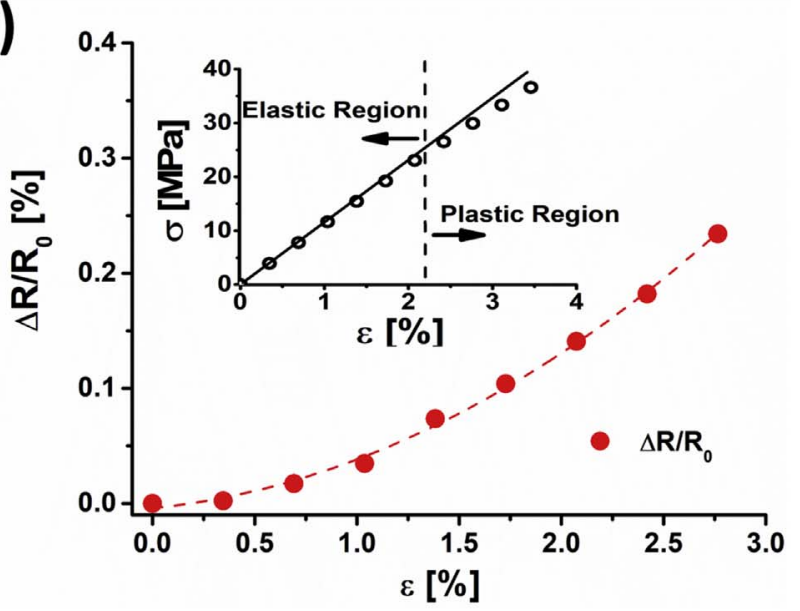

Fig. 6. a) Schematic of the 3-point bending tests apparatus; b) Corresponding normalized resistance change $\left(\Delta R / R_{0}\right)$. In the inset, the stress-strain curve. 

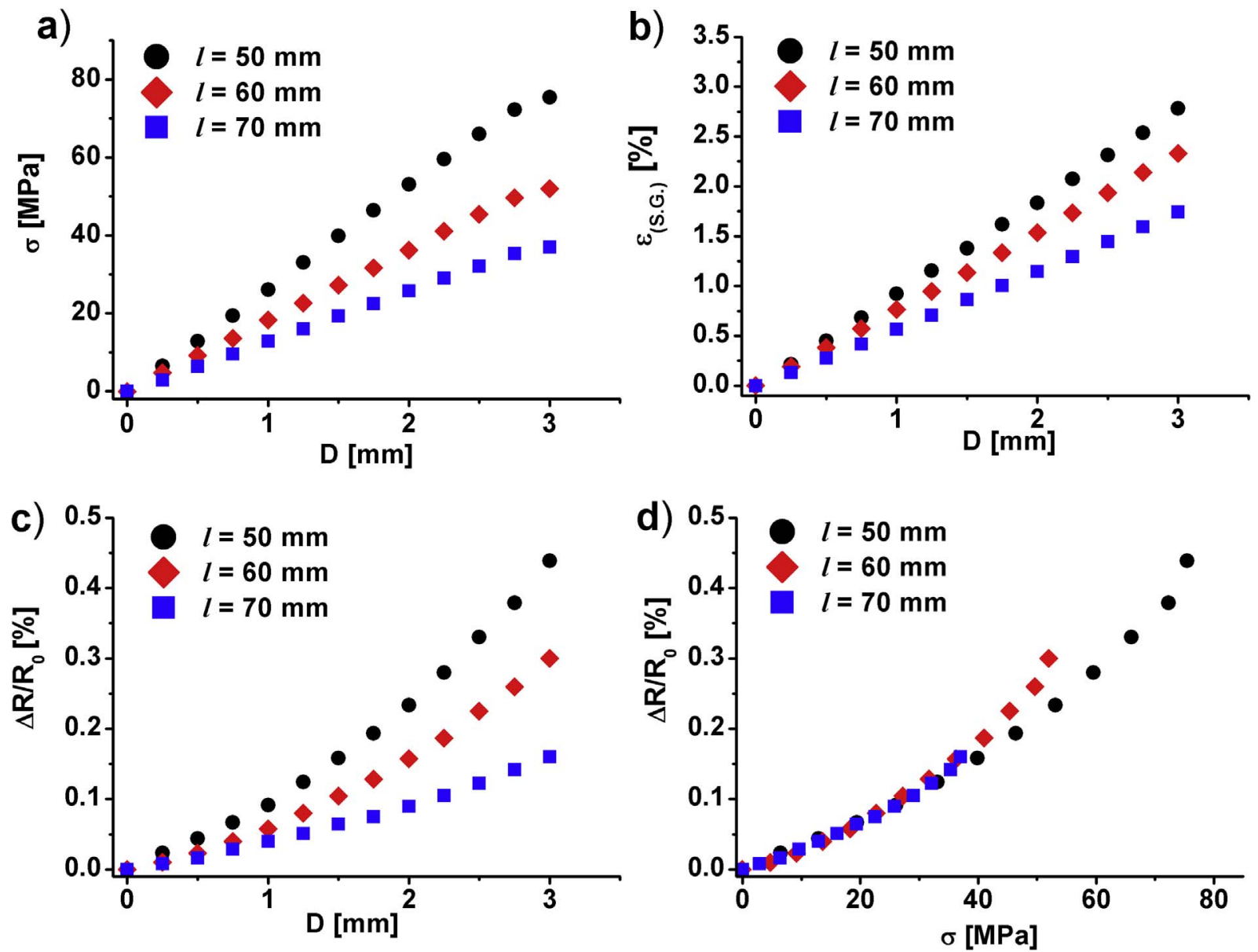

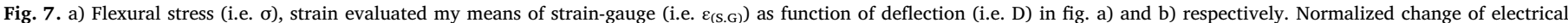
resistance (i.e. $\Delta$ R/R $R_{0}$ ) vs. deflection (i.e. D) and flexural stress (i.e. $\sigma$ ) in fig. c) and d) respectively.

$\frac{\Delta R}{R_{0}}=(1+\varepsilon)\left(\exp ^{\tau \varepsilon}-1\right)$

The exponent $\tau$ is related to the square root of the energy barrier (i.e. $E_{c}$ ), the electron mass (i.e. $m$ ) and the interparticle separation distance (i.e. $d_{o}$ ) according to the following equation:

$\tau=2 \frac{\sqrt{2 m E_{c}}}{\hbar} d_{0}$

where $\hbar$ denote the Planck's constant divided by $2 \pi$. Fig. 8 shows the dependence of normalized resistance change $\Delta R / R_{0}$ on strain $\varepsilon$ for different lengths of the support span (i.e. $l$ ) and the same dependence (i.e. model) predicted by the electrical transport based on tunneling (eq.

(5)). In particular, the data reported have been plotted by using $\tau$ as fit parameter up to reach the maximum for the regression coefficient $\left(\mathrm{R}^{2}\right.$ close to 1 ).

For a given level of strain (i.e. $\varepsilon$ ), the resistance changes $\Delta R / R_{0}$ are higher when a short distance configuration of support span (i.e. $l=50 \mathrm{~mm})$ is adopted for the flexural tests. This result reflect the previous considerations since, at the same strain, differences in the span lengths lead to different deflections (i.e. $D$ ) and therefore different loads (i.e. $\sigma$ ). As a consequence the percolating network undergoes larger deformations which can be evidenced by the electrical measurements (i.e. $\Delta R / R_{0}$ ). Moreover, once the value of $\tau$ has been estimated, with reference to eq. (6) and assuming a value of $0.5 \mathrm{eV}$ for the energy barrier $E_{c}$, coherently with values found for the adopted resin [56], it is possible to estimate the average inter-particle distance $d_{o}$ between the nanotubes of the current percolating network under flexural strains by
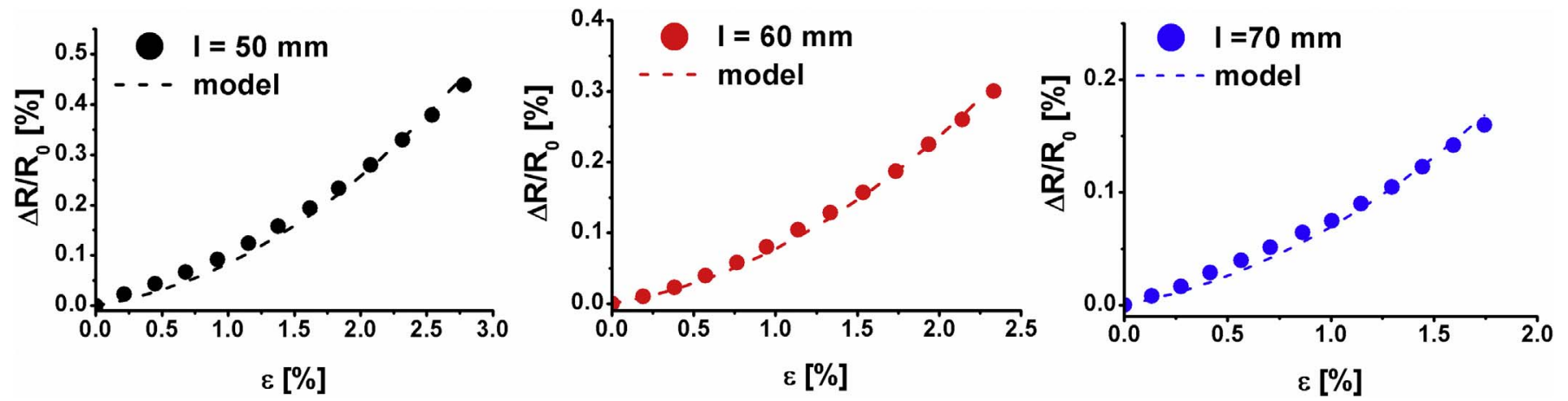

Fig. 8. Experimental and estimated normalized resistance change $\left(\Delta R / R_{0}\right)$ versus strain for different lengths of support span. 


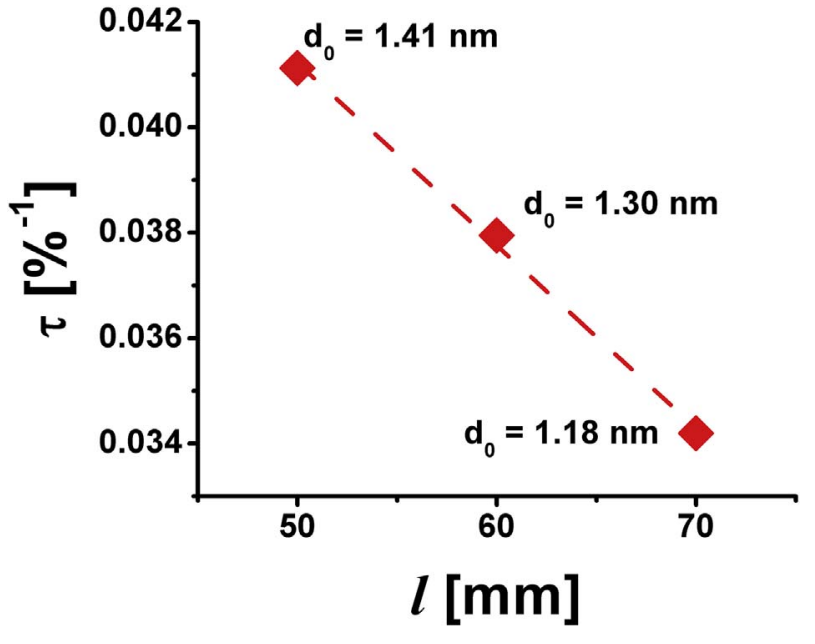

Fig. 9. Fit parameter $\tau$ versus length of support span and estimate average inter-particle distance $d_{o}$ between the nanotubes.

means of the inverse equation:

$d_{0}=\frac{\tau \hbar}{2 \cdot \sqrt{2 m E_{c}}}$

Fig. 9 shows the values of $\tau$ found by the fitting procedure as function of the length of the support span (i.e. $l$ ) and the relative distance $\mathrm{d}_{0}$, expressed in nanometers, which is consistent with those already determined for the same material [47]. As expected from theory and previously discussed mechanical analysis, inter-particle distance (i.e. d0) decreases with an increasing length of the span since a lower load affects more weakly the CNTs network inside the polymer. In any case, the average values estimated for such distances always falls in the theoretical range $[0.034 \div 2] \mathrm{nm}$ where the lower and upper limit are imposed by the minimum distance between two carbonaceous particles due to the Wan der Walls interactions and maximum distance provided for the electric conduction between two particles by tunneling, respectively. In this framework, given the importance of the distance between adjacent CNTs on the tunneling-type contact resistance and therefore on the electrical transport properties of nanofilled resin, analytical and numerical studies to estimate it rather than to evaluate it through complex morphological analysis are particularly required. In Ref. [57], based on the inter-nanotube distance variation, an analytical model is proposed in order to predict the electrical resistance change in CNT-based polymer composites due to mechanical deformation. A good correlation between numerical and experimental results is obtained, although the calibration of several parameters related to the geometrical contact configuration and the initial tunneling distance are needed. In Ref. [58] the interparticle distance that coincides with the thickness of the insulating polymer wrapped around the filler is assessed solving an equation involving a Lambert function. Furthermore, in Ref. [59] an analytical prediction of the inter-nanotube matrix thickness as function of the nanofiller volume fraction is presented, finding a power law relationship between the parts. In this paper the authors present a different and simple analytical approach to evaluate this parameter based on piezoresistive observations of the nano-reinforced material.

\section{Conclusions}

Structural damage remains a critical issue for polymer composites components employed in the aeronautical sector. A suitable strategy to face such a problem is structural health monitoring (SHM) achieved by integrating sensors inside the structure thus providing real-time measurements also in inaccessible areas. In the present work, strain sensing properties of a structural resin suitable for aircraft applications loaded with $0.3 \mathrm{wt} \%$ of MWCNTs was investigated in tension and flexural tests for their potential usage in self-identifying structural damages. A thermal and dynamic mechanical analysis carried out on the composites has revealed a storage modulus higher than $2000 \mathrm{MPa}$ in a wide temperature range thus confirming their reliability if employed as structural aeronautical parts working in the normal operational temperature range. The analysis of some coefficients of an analytical equation has been proposed in order to evaluate the dynamic durability of the sensor in terms of mechanical integrity and electrical functionality when it is subject to a subsequent stretching/releasing cycles at different level of strains. Moreover, an estimation of the interparticle distances between the CNTs in the conductive network formed within the polymeric matrix as function of the bending deformations has been carried out by means of theoretical and statistical analysis. The obtained results allow to design strain sensors with tailored piezoresistive behaviors for realtime structural health monitoring in aeronautic applications. For these purposes, future works will attempt to analyze composites, reinforced with different concentrations and type of nanofillers like carbon fibers or graphene sheets, under long-term tests of different loading-unloading strain cycles.

\section{Acknowledgments}

This work was supported by EU FP7 project FP7-604391 GRAPHENE Flagship, H2020- Adhoc-2014-20 project GA 696656 Graphene Core1 and within the framework of the Marie SkłodowskaCurie Actions (MSCA) Research and Innovation Staff Exchange (RISE) H2020-MSCA-RISE-2016, Project Acronym: Graphene 3D - Project Number: 734164.

\section{References}

[1] Guadagno L, Raimondo M, Vittoria V, Vertuccio L, Naddeo C, Russo S, De Vivo B, Lamberti P, Spinelli G, Tucci V. Development of epoxy mixtures for application in aeronautics and aerospace. RSC Adv 2014;4:15474-88.

[2] Kotsilkova R, Todorov P, Ivanov E, Kaplas T, Svirko Y, Paddubskaya A, Kuzhir P. Mechanical properties investigation of bilayer graphene/poly(methyl methacrylate) thin films at macro, micro and nanoscale. Carbon 2016;100:355-66.

[3] Vertuccio L, Guadagno L, Spinelli G, Russo S, Iannuzzo G. Effect of carbon nanotube and functionalized liquid rubber on mechanical and electrical properties of epoxy adhesives for aircraft structures. Compos. Part B 2017;129:1-10.

[4] Guadagno L, Vietri U, Raimondo M, Vertuccio L, Barra G, De Vivo B, Lamberti P, Spinelli G, Tucci V, De Nicola F, Volponi R, Russo S. Correlation between electrical conductivity and manufacturing processes of nanofilled carbon fiber reinforced composites. Compos. Part B 2015;80:7-14.

[5] Guadagno L, Naddeo C, Raimondo M, Barra G, Vertuccio L, Sorrentino A, Binder WH, Kadlec M. Development of self-healing multifunctional materials. Compos. Part B 2017;128:30-8.

[6] Kreculj D, Rašuo B. Review of impact damages modelling in laminated composite aircraft structures. Teh Vjesn 2013;20:485-95.

[7] Polimeno U, Meo M. Detecting barely visible impact damage detection on aircraft composites structures. Compos Struct 2009;91:398-402.

[8] Staszewski W, Boller C, Tomlinson GR. Health monitoring of aerospace structures: smart sensor technologies and signal processing. United Kingdom: John Wiley \& Sons; 2004.

[9] Kang I, Schulz MJ, Kim JH, Shanov V, Shi D. A carbon nanotube strain sensor for structural health monitoring. Smart Mater Struct 2006;15:737-48.

[10] Kang I, Heung Y-Y, Kim J-H, Lee J-W, Gollapudi R, Subramaniam S, Narasimhadevara S, Hurd D, Kirikera GR, Shanov V, Schulz M-J, Shi D, Boerio J, Mall S, Ruggles-Wren M. Introduction to carbon nanotube and nanofiber smart materials. Compos. Part B 2006;37:382-94.

[11] De Vivo B, Lamberti P, Spinelli G, Tucci V, Vertuccio L, Vittoria V. Simulation and experimental characterization of polymer/carbon naotubes composites for strain sensor applications. J Appl Phys 2014;116:054307-14.

[12] Hu N, Karube Y, Arai M, Watanabe T, Yan C, Li Y, Liu Y, Fukunaga Y. Investigation on sensitivity of a polymer/carbon nanotube composite strain sensor. Carbon 2010;48(48):680-7.

[13] Tombler TW, Zhou C, Alexseyev L, Kong J, Dai H, Liu L, Jayanthi CS, Tang M, Wu SY. Reversible electromechanical characteristics of carbon nanotubes under localprobe manipulation. Nature 2000;405:769-72.

[14] Wang S, Chung DDL, Chung JH. Self-sensing of damage in carbon fiber polymer-matrix composite cylinder by electrical resistance measurement. J Intell Mater Syst Struct 2006;10:853-61.

[15] Park S, Shin H-H, Yun C-B. Wireless impedance sensor nodes for functions of structural damage identification and sensor self-diagnosis. Smart Mater Struct 2009;18:18. 055001-(11pp). 
[16] Lopez I, Sarigul-Klijn N. A review of uncertainty in flight vehicle structural damage monitoring, diagnosis and control: challenges and opportunities. Prog Aero Sci 2010;46:247-73.

[17] Diamanti K, Soutis C. Structural health monitoring techniques for aircraft composite structures. Prog Aero Sci 2010;46:342-52.

[18] Gonçalves BF, Oliveira J, Costa P, Correia V, Martins P, Botelho G, LancerosMendez S. Development of water-based printable piezoresistive sensors for large strain applications. Compos. Part B 2017;112:344-52.

[19] Bouhamed A, Al-Hamry A, Müller C, Choura S, Kanoun O. Assessing the electrical behaviour of MWCNTs/epoxy nanocomposite for strain sensing. Compos. Part B 2017;128:91-9.

[20] Kim SW, Kim EH, Jeong MS, Lee I. Damage evaluation and strain monitoring for composite cylinders using tin-coated FBG sensors under low-velocity impacts. Compos. Part B 2015;74:13-22.

[21] Costa P, Silva J, Ansón-Casaos A, Martinez MT, Abad MJ, Viana J, Lanceros-Mendez S. Effect of carbon nanotube type and functionalization on the electrical, thermal, mechanical and electromechanical properties of carbon nanotube/styrene-butadiene-styrene composites for large strain sensor applications. Compos. Part B 2014;61:136-46.

[22] Koecher MC, Pande JH, Merkley S, Henderson S, Fullwood DT, Bowden AE. Piezoresistive in-situ strain sensing of composite laminate structures. Compos. Part B 2015;69:534-41.

[23] Amjadi M, Kyung KU, Park I, Sitti M. Stretchable, skin-mountable, and wearable strain sensors and their potential applications: a review. Adv Funct Mater 2016;26:1678-98.

[24] Mei H, Zhang C, Wang R, Feng J, Zhang T. Impedance characteristics of surface pressure-sensitive carbon black/silicone rubber composites. Sens. Actuat. A Phys. 2015;233:118-24.

[25] Wang SL, Wang P, Ding TH. Piezoresistivity of silicone-rubber/carbon black composites excited by Ac electrical field. J Appl Polym Sci 2009;113:337-41.

[26] Mohanraj GT, K Chaki T, Chakraborty A, Khastgir D. Effect of some service conditions on the electrical resistivity of conductive styreneebutadiene rubbere carbon black composites. J Appl Polym Sci 2004;82:2179-88.

[27] Brosseau C, NDong W, Mdharhri A. Influence of uniaxial tension on the microwave absorption properties of filled polymers. J Appl Phys 2008;104. 074907-1 074907-7.

[28] Vertuccio L, Guadagno L, Spinelli G, Lamberti P, Tucci V, Russo S. Piezoresistive properties of resin reinforced with carbon nanotubes for health-monitoring of aircraft primary structures. Compos. Part B 2016;107:192-202.

[29] ASTM D638. Standard test method for tensile properties of plastics. West Conshohocken, PA: ASTM International; 2010.

[30] ASTM D790. Standard test methods for flexural properties of unreinforced and reinforced plastics and electrical insulating. ASTM International; 2010.

[31] Guadagno L, Raimondo M, Vertuccio L, Mauro M, Guerra G, Lafdi K, De Vivo B, Lamberti P, Spinelli G, Tucci V. Optimization of graphene-based materials outperforming host matrices. RSC Adv 2015;5:36969-78.

[32] Oliva-Avilés A, Avilés F, Sosa V. Electrical and piezoresistive properties of multiwalled carbon nanotube/polymer composite films aligned by an electric field. Carbon 2011;49:2989-97.

[33] Ku-Herrera JJ, Aviles F. Cyclic tension and compression piezoresistivity of carbon nanotube/vinyl ester composites in the elastic and plastic regimes. Carbon 2012;50:2592-8.

[34] Pham GT, Park YB, Liang Z, Zhang C, Wang B. Processing and modeling of conductive thermoplastic/carbon nanotube films for strain sensing. Compos B Eng 2008;39:209-16.

[35] Vertuccio L, Vittoria V, Guadagno L, De Santis F. Strain and damage monitoring in carbon-nanotube-based composite under cyclic strain. Compos. Part A-Appl S 2015;71:9-16.

[36] Ferreira A, Rocha JG, Ansòn-Casaos A, Martìnez MT, Vaz F, Lanceros-Mendez S. Electromechanical performance of poly(vinylidene fluoride)/carbon nanotube composites for strain sensor applications. Sensor Actuat. A-Phys. 2012;178:10-6.

[37] Simoes R, Silva J, Vaia R, Sencadas V, Costa P, Gomes J, Lanceros-Mèndez S. Low percolation transitions in carbon nanotube networks dispersed in a polymer matrix: dielectric properties, simulations and experiments. Nanotechonlogy
2009;20:035703. (8pp).

[38] Paleo-Vieto AJ, van Hattum F, Pereira J, Rocha JG, Silva J, Sencadas V, LancerosMèndez S. The piezoresistive effect in polypropylene the piezoresistive effect in polypropylene-carbon nanofibre composites obtained by shear extrusion. Smart Mater Struct 2010;19:065013. (7pp).

[39] Park M, Kim H, Youngblood JP. Strain-dependent electrical resistance of multiwalled carbon nanotube/polymer composite films. Nanotechnology 2008; 19:055705-7.

[40] Wichmann MHG, Buschhorn ST, Gehrmann J, Schulte K. Piezoresistive response of epoxy composites with carbon nanoparticles under tensile load. Phys Rev B 2009;80. 245437-1; 245437-8.

[41] Yang L, Han J. Electronic structure of deformed carbon nanotubes. Phys Rev Lett 2000;85:154-7.

[42] Guadagno L, De Vivo B, Di Bartolomeo A, Lamberti P, Sorrentino A, Tucci V, Vertuccio L, Vittoria V. Effect of functionalization on the thermo-mechanical and electrical behavior of multi-wall carbon nanotube/epoxy composites. Carbon 2011;49:1919-30.

[43] Allaoui A, El Bounia N. How carbon nanotubes affect the cure kinetics and glass transition temperature of their epoxy composites? - A review. Express Polym Lett 2009;3:588-94.

[44] Vertuccio L, Russo S, Raimondo M, Lafdi K, Guadagno L. Influence of carbon nanofillers on the curing kinetics of epoxy-amine resin. RSC Adv 2015;5:90437-50.

[45] Stutz H. Lifetime assessment of epoxies by the kinetics of thermal degradation. J Appl Polym Sci 2004;91:1881-6.

[46] Smith WF, Hashemi J. Foundations of materials science and engineering. Singapur: McGraw-Hill; 1993.

[47] Li C, Thostenson ET, Chou TW. Dominant role of tunneling resistance in the electrical conductivity of carbon nanotube-based composites. Appl Phys Lett 2007;91. 223114-3.

[48] De Vivo B, Lamberti P, Spinelli G, Tucci V. A morphological and structural approach to evaluate the electromagnetic performances of composites based on random networks of carbon nanotubes. J Appl Phys 2014;115:154311-2.

[49] Böger L, Wichmann MH, Meyer LO, Schulte K. Load and health monitoring in glass fibre reinforced composites with an electrically conductive nanocomposite epoxy matrix. Compos Sci Technol 2008;68:1886-94.

[50] Alian AR, El-Borgiand S, Meguid SA. Multiscale modeling of the effect of waviness and agglomeration of CNTs on the elastic properties of nanocomposites. Comput Mater Sci 2016;117:195-204.

[51] Gong S, Zhu ZH, Meguid SA. Carbon nanotube agglomeration effect on piezoresistivity of polymer nanocomposites. Polymer 2014;55:5488-99.

[52] Wu S, Ladani RB, Zhang J, Ghorbani K, Zhang X, Mouritz AP, Kinloch AJ, Wang CH. Strain sensors with adjustable sensitivity by tailoring the microstructure of graphene aerogel/PDMS nanocomposites. ACS Appl Mater Interfaces 2016;8:24853-61.

[53] Myers RH, Montgomery DC. Response surface methodology: process and product optimization using designed experiments. Canada: John Wiley \& Sons; 2002.

[54] Meola C, Carlomagno GM, Bonavolontà C, Valentino M. Monitoring composites under bending tests with infrared thermography. Adv Opt Technol 2012;2012:7.

[55] Bonavolontà C, Carmelingo C, Carotenuto G, De Nicola S, Longo A, Meola C, Boccardi S, Palomba M, Pepe GP, Valentino M M. Characterization of piezoresistive properties of graphene-supported polymer coating for strain sensor applications. Sens Actuators A 2016;252:26-34.

[56] Hu N, Karube Y, Arai M, Watanabe T, Yan C, Li Y, Liu Y, Fukunaga H. Investigation on sensitivity of a polymer/carbon nanotube composite strain sensor. Carbon 2010;48:680-7.

[57] Kuronuma Y, Takeda T, Shindo Y, Narita F, Wei Z. Electrical resistance-based strain sensing in carbon nanotube/polymer composites under tension: analytical modeling and experiments. Compos Sci Technol 2012;72:1678-82.

[58] Panozzo F, Zappalorto M, Quaresimin M. Analytical model for the prediction of the piezoresistive behavior of CNT modified polymers. Compass Part B 2017;109:53-63.

[59] Takeda T, Shindo Y, Kuronuma Y, Narita F. Modeling and characterization of the electrical conductivity of carbon nanotube-based polymer composites. Polymer 2011;52:3852-6. 